$\pm N / E$

Global burnals Inc.

है ?

\title{
The Risk Factors for Development of Emergency Conditions in Tender-Age Infants in Acute Intestinal Infections of Different Etiologies
}

\author{
By Z.M. Kuliyeva, L.I. Rustamova, M.N. Mammadova, \\ I.B. Israfilbekova \& T.I. Ibadova
}

Abstract- Among the leading risk factors for the development of emergency conditions in acute intestinal infections, especially in infants, some authors point to rickets, anemia, and abnormal antenatal pathology.

The aim is to determine the frequency of occurrence of various risk factors for the development of emergency situations in tender-age infants.

Materials and methods: 338 tender-age infants with urgent conditions were under observation. The study involved clinical-anamnestic, bacteriological, and serological methods.

The aggravating factors were as follows: diseases of parents in $16(6.2 \%)$, related marriages - 20 (7.7\%) pregnancy pathology-137 (52.9\%), prematurity-16 (6.2\%), artificial feeding - 127 (49.0\%), early diseases (acute respiratory viral infections, pneumonia, encephalopathy, intestinal infections).

Results: According to the results of the study, the central nervous system damage was most often observed in children from 1 month to 6 months (80.2\%), anemia was more detected in children of $1-3$ years $-56.4 \%$, rickets was more diagnosed in children aged 6-12 months $-38.2 \%$.

GJMR-F Classification: NLMC Code: WI 400

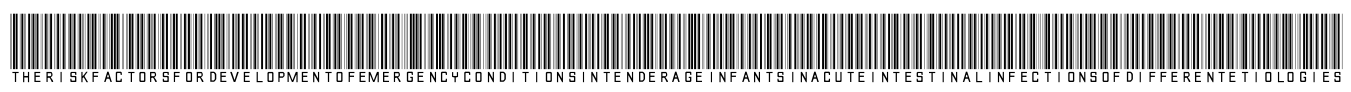

Strictly as per the compliance and regulations of:

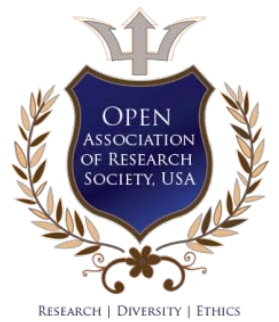

(c) 2021. Z.M. Kuliyeva, L.I. Rustamova, M.N. Mammadova, I.B. Israfilbekova \& T.I. Ibadova. This research/review article is distributed under the terms of the Attribution-NonCommercial-NoDerivatives 4.0 International (CC BY-NC-ND 4.0). You must give appropriate credit to authors and reference this article if parts of the article are reproduced in any manner. Applicable licensing terms are at https://creativecommons.org/licenses/by-nc-nd/4.0/. 


\title{
The Risk Factors for Development of Emergency Conditions in Tender-Age Infants in Acute Intestinal Infections of Different Etiologies
}

\author{
ФАКТОРЫ РИСКА РАЗВИТИЯ НЕОТЛОЖНЫХ СОСТОЯНИЙ У ДЕТЕЙ РАННЕГО \\ ВОЗРАСТА ПРИ ОСТРЫХ КИШЕЧНЫХ ИНФЕКЦИЯХ РАЗЛИЧНОЙ ЭТИОЛОГИИ
}

\author{
Z.M. Kuliyeva ${ }^{\alpha}$, L.I. Rustamova ${ }^{\sigma}$, M.N. Mammadova $^{\circ}$, I.B. Israfilbekova $^{\omega} \&$ T.I. Ibadova ${ }^{*}$
}

Abstract- Among the leading risk factors for the development of emergency conditions in acute intestinal infections, especially in infants, some authors point to rickets, anemia, and abnormal antenatal pathology.

The aim is to determine the frequency of occurrence of various risk factors for the development of emergency situations in tender-age infants.

Materials and methods: 338 tender-age infants with urgent conditions were under observation. The study involved clinicalanamnestic, bacteriological, and serological methods.

The aggravating factors were as follows: diseases of parents in $16(6.2 \%)$, related marriages - $20(7.7 \%)$ pregnancy pathology-137 (52.9\%), prematurity-16 (6.2\%), artificial feeding - 127 (49.0\%), early diseases (acute respiratory viral infections, pneumonia, encephalopathy, intestinal infections).

Results: According to the results of the study, the central nervous system damage was most often observed in children from 1 month to 6 months $(80.2 \%)$, anemia was more detected in children of $1-3$ years $-56.4 \%$, rickets was more diagnosed in children aged $6-12$ months $-38.2 \%$. Toxic-dystrophic condition (5.8\%) and allergic diathesis $(6.6 \%)$ were much less common. In 224 patients with central nervous system lesions, most of the patients were on mixed $-44.2 \%$ and artificial $-42.4 \%$ feeding, significantly less were breastfed - 13.3\%.

The second place in the frequency of diseases of the premorbid background was occupied by anemia with artificial feeding (45.2\%), less with mixed feeding (41.7\%) and much less often with breastfeeding (13.0). The highest incidence of rickets was observed with mixed feeding in $44.0 \%$, the lowest with artificial $-41.05 \%$, and less often with breastfeeding - in $14.5 \%$ of children.

It is known that breastfeeding reduces the incidence of acute intestinal infections in tender-age infants. This is proved by the fact that in children of the first 3 months the

Author $\alpha$ : Doctor of Medical Sciences of the Department of Pediatrics of the Azerbaijan State Institute for Advanced Training of Doctors named after A. Aliyev, Baku, Azerbaijan. e-mail: doctor-zema@mail.ru

Author o: Candidate of Medical Sciences, Associate Professor, Head of the Virology Departments of the V. Yu. Akhundov Research Institute of Medical Prevention, Baku, Azerbaijan.

e-mail: lala.rustamova.1967@mail.ru

Author p: Candidate of Medical Sciences, Associate Professor of the Department of Infectious Diseases of the Azerbaijan Medical University, Baku, Azerbaijan.e-mail: lala.rustamova.1967@mail.ru

Author w: Resident of the Department of Pediatrics of the Azerbaijan State Institute for Advanced Training of Doctors named after A. Aliyev, Baku, Azerbaijan. e-mail: doctor-zema@mail.ru incidence of acute intestinal infections is much less frequent compared to children who are on artificial feeding.

Conclusions: It is found that the risk factors for the development of emergency conditions in tender-age infants with acute intestinal infections exacerbate physiological immunodeficiency, and severe rickets, a violation of vitamin Dmetabolism in intestinal infections of bacterial and bacterialviral etiology leads to emergency conditions in tender-age infants.

\section{Вступление}

реди ведущих факторов риска развития
неотложных состояний при острых кишечных
инфекциях (ОКИ), особенно у детей грудного возраста, некоторые авторы указывают на рахит, анемию, нарушение питания и антенатальную патологию.

Несомненно, выраженная гипотрофия, анемия сопровождаются снижением иммунитета и более тяжелым течением бактериальной кишечной инфекции, которая является основной причиной смертности детей $[3,4,11,12]$.

При этом, изучение статистическими методами роли преморбидных факторов в развитии неотложных состояний при ОКИ оказались малоинформативными и не раскрывают сущность поставленной задачи. Но судить о повышенной восприимчивости этих детей к инфекции на основании статистических данных трудно, так как эти дети находятся под влиянием и других неблагоприятных факторов $[1,2,5,9]$.

Однако, в настоящее время влияние биологических факторов значительно уступает социально-культурным, таким, как многодетность, неполная семья, диссоциальное поведение родителей и т. д. Учитывая, что в литературе имеются скудные данные о влиянии преморбидных факторов на развитие неотложных состояний при ОКИ у детей $[6-8,10]$ перед нами была поставлена задача наиболее полное определение роли этих факторов в указанной патологии в зависимости от возраста детей, характера вскармливания и этиологии. 


\section{I. Материалы и Методы Исследования}

Из 338 наблюдаемых нами детей при ОКИ с неотложными состояниями неблагоприятный преморбидный фон выявлен у 76,6 \%: поражение центральной нервной системы - у 86,5\%, анемия -у $56,4 \%$, рахит- у 45,5\%, гипотрофия - у $36,6 \%$, аллергический диатез- у $8,5 \%$ и токсикодистрофическое состояние (ТДС) - 5,8\%. При этом отягощающими факторами были: болезни родителей - у $6,1 \%$, родственные браки - 7,7\%, патология беременности - 52,9\% и родов - 23,9\%, недоношенность - 6,2\%, раннее искусственное вскармливание - 49,0\% и смешанное - у 40,9\% и ранее перенесенные болезни $-58,3 \%$ ( острые респираторные вирусные инфекции, пневмония, энцефалопатия + кишечные инфекции и др).

В зависимости от возраста больные дети были разделены на 3 группы: до 6 мес., 7-12 мес., 1-3 года. При этом изучалась частота встречаемости преморбидного фона в зависимости от возраста, что представлена в таблице 1 .

Таблища 1: Частота заболеваний преморбидного фона в зависимости от возраста детей с неотложными состояниями

\begin{tabular}{|c|c|c|c|c|}
\hline \multirow{2}{*}{$\begin{array}{c}\text { Факторы преморбидного } \\
\text { фона }\end{array}$} & \multicolumn{3}{|c|}{ Возраст детей } & \multirow{2}{*}{$\begin{array}{c}\text { Степень зависимости } \\
\text { от возраста }\end{array}$} \\
\hline & $\begin{array}{c}0-6 \text { мес. } \\
n=101\end{array}$ & $\begin{array}{c}7-12 \text { мес } \\
n=110\end{array}$ & $\begin{array}{c}1-3 \text { года } \\
\mathrm{n}=127 \\
\end{array}$ & \\
\hline Поражение ЦНС & $80,2 \%$ & $70,9 \%$ & $51,2 \%$ & $x^{2}=22.8, p<0.001$ \\
\hline Анемия & $37,6 \%$ & $41,8 \%$ & $48,8 \%$ & $x^{2}=3, p>0.05$ \\
\hline Рахит & $34,7 \%$ & $51,8 \%$ & $20,5 \%$ & $x^{2}=25.5, p<0.001$ \\
\hline Гипотрофия & $36,6 \%$ & $38,2 \%$ & $12,6 \%$ & $x^{2}=24.3, p<0.001$ \\
\hline Аллергический диатез & $6,9 \%$ & $8,2 \%$ & $4,7 \%$ & $x^{2}=1.2, p>0.05$ \\
\hline ТДС & $3,0 \%$ & $6,4 \%$ & $3,9 \%$ & $x^{2}=1.6, p>0.05$ \\
\hline
\end{tabular}

Из приведенной таблицы 1 видно, что из общего количества 338 больных наиболее часто наблюдалось поражение ЦНС - в 80,2\% случаях в до 6 мес., несколько меньше в возрасте 6-12 мес - 70,9\% и 13 года - 51,2\% среди них энцефалопатия-у 17 (7,6\%), гипоксическая - у 25,4\%, перинатальная - у 34,3\%, токсическая - у 21,9\%. Следует отметить, что поражение ЦНС у 24 детей было в сочетанном виде: энцефалопатия перинатальная +гипоксическая, энцефалопатия гипоксическая+токсическая и др. Второе же место по частоте заболеваний преморбидного фона занимала анемия - в 43,2\% случаях (0-6 мес. - 37,6\%, 7-12 мес. - 41,8\%,1-3 года$56,4 \%$ ). Рахит диагностирован у 34,9\% (0-6 мес. $34,65 \%, 7-12$ мес. - 38,18\%, 1-3 года - 20,7\%), гипотрофия - у 28,10\% (0-6 мес. - 36,6\%, 6-12 мес. $38,2 \%$, 1-3 года - 14,5\%). Значительно реже встречалось ТДС - у 5,8\% и аллергический диатез - у 6,6\% больных.

Нами выявлено ТДС у больных с ОКИ находящихся в реанимационном отделении, в то время как некоторые авторы указывают на диапазон встречаемости ТДС при данной патологии от 4\% до 30\%. Несмотря на то, что ТДС у больных при ОКИ с неотложными состояниями встречалось редко, но оказывало значительное влияние на тяжесть, течение болезни и на исход. Из 14 больных на фоне проведенной соответствующей терапии 11 с улучшением переведены в отделение для дальнейшего лечения. 1 больной с улучшением выписался домой на дальнейшее амбулаторное лечение под наблюдением участкового врача, 2 больных соответственно в крайне тяжелом и очень тяжелом состоянии продолжали лечение в реанимационном отделении.

Клинически у них отмечалась адинамия, мышечная гипотония, сухость и бледность кожных покровов, нарушение терморегуляции, отсутствие аппетита, увеличение печени, продолжительный диарейный синдром, которые повлияли на прогрессирование гипотрофии и нарастанию интоксикации, изменение со стороны периферической крови в виде гипохромной анемии, лейкоцитоз, увеличение скорости оседания эритроцитов (СОЭ). При изучении биохимических показателей крови выявились изменения со стороны протеинограммы, а именно снижение количества общего белка, диспротеинемии и снижение уровня калия и натрия в сыворотке.

Развитие токсико-дистрофического состояния значительно утяжаляло состояние больных. Этиологической причиной токсико-дистрофического состояния у наших больных были сочетанные бактериальные инфекции, при которых диссеминированность процесса способствовала постепенному вовлечению различных органов и систем. В основе патогенеза его развития лежит острая белковоэнергетическая недостаточность, а катаболизм белков 
приводит к резкому снижению секреции пищеварительных ферментов. Накапливающиеся нерасщепленные пищевые продукты, повышая осмотическую концентрацию кишечного содержимого усиливают перистальтику.

Наряду с вышеуказанными факторами на развитие неотложных состояний у детей раннего возраста при ОКИ также оказывали влияние болезни родителей, родственные браки, порядковый номер беременности и родов, течение беременности первой и второй половины, течение родов, доношенность ребенка, характер вскармливания, перенесенные заболевания.

Вышеизложенные данные наглядно представлены в таблице 2.

Таблица 2: Факторы, способствующие развитию неотложных состояний при ОКИ различной этиологии

\begin{tabular}{|c|c|c|c|c|c|c|}
\hline \multirow{3}{*}{ Факторы } & \multicolumn{6}{|c|}{ Острые кишечные инфекции } \\
\hline & \multicolumn{2}{|c|}{$\begin{array}{c}\text { Бактериальная } \\
(n=110)\end{array}$} & \multicolumn{2}{|c|}{$\begin{array}{c}\text { Вирусная } \\
(n=47)\end{array}$} & \multicolumn{2}{|c|}{$\begin{array}{c}\text { Бактериально- } \\
\text { вирусная } \\
(n=119) \\
\end{array}$} \\
\hline & абс. & $\%$ & абс. & $\%$ & абс. & $\%$ \\
\hline Болезни родителей & 6 & 5,5 & 3 & 6,4 & 7 & 5,8 \\
\hline Родственные браки & 8 & 7,3 & 2 & 4,3 & 10 & 8,4 \\
\hline \multicolumn{7}{|l|}{ № беременности: } \\
\hline Первая & 41 & 37,3 & 21 & 44,7 & 43 & 36,1 \\
\hline Вторая и более & 69 & & 26 & & 76 & \\
\hline \multicolumn{7}{|l|}{ № родов: } \\
\hline Первые & 43 & 39,1 & 20 & 42,6 & 41 & 34,5 \\
\hline Вторые и более & 62 & 56,3 & 22 & 46,8 & 71 & 59,6 \\
\hline \multicolumn{7}{|l|}{ Течение I половины беременности: } \\
\hline Токсикоз & 31 & 28,2 & 20 & 42,6 & 24 & 20,2 \\
\hline Внутриутробная инфекция & 1 & 0,9 & 1 & 2,1 & 5 & 4,2 \\
\hline Угроза прерывания беременности & 2 & 1,8 & - & - & 2 & 1,7 \\
\hline Другие & 5 & 4,5 & 2 & 4,3 & 1 & 0,8 \\
\hline Всего & 39 & 35,5 & 23 & 48,9 & 32 & 26,9 \\
\hline \multicolumn{7}{|l|}{ Течение II половины беременности: } \\
\hline Токсикоз & 14 & 12,7 & 5 & 10,6 & 13 & 10,9 \\
\hline Внутриутробная инфекция & 2 & 1,8 & - & - & 1 & 0,8 \\
\hline Угроза прерывания беременности & - & - & - & - & - & -- \\
\hline Другие & 2 & 1,8 & 5 & 10,6 & 1 & 0,8 \\
\hline Всего & 18 & 16,4 & 10 & 21,3 & 15 & 12,6 \\
\hline \multicolumn{7}{|l|}{ Роды: } \\
\hline Физиологические & 87 & 79,1 & 37 & 78,7 & 90 & 75,6 \\
\hline Патологические & 23 & 20,9 & 10 & 21,3 & 29 & 24,4 \\
\hline
\end{tabular}


Продолжение таблицы .2.

\begin{tabular}{|c|c|c|c|c|c|c|}
\hline \multirow{3}{*}{ Факторы } & \multicolumn{6}{|c|}{ Острые кишечные инфекции } \\
\hline & \multicolumn{2}{|c|}{$\begin{array}{c}\text { Бактериальная } \\
(\mathrm{n}=110)\end{array}$} & \multicolumn{2}{|c|}{$\begin{array}{c}\text { Вирусная } \\
(n=47)\end{array}$} & \multicolumn{2}{|c|}{$\begin{array}{c}\text { Бактериально- } \\
\text { вирусная } \\
(n=119)\end{array}$} \\
\hline & абос. & $\%$ & абс. & $\%$ & аб.c. & $\%$ \\
\hline \multicolumn{7}{|l|}{ Перенесенные заболевания: } \\
\hline Асфиксия & 17 & 15,5 & 2 & 4,3 & 17 & 14,3 \\
\hline энцефалопатия & 7 & 6,4 & 7 & 14,9 & 4 & 3,4 \\
\hline Кишечная инфекция & 12 & 10,9 & 1 & 2,1 & 11 & 9,2 \\
\hline Асфиксия + энцефалопатия & 8 & 7,3 & 4 & 8,5 & 10 & 8,4 \\
\hline Асфиксия +кишечная инфекция & 3 & 2,7 & 1 & 2,1 & 4 & 3,4 \\
\hline Другие & 16 & 14,5 & 8 & 17,0 & 19 & 15,9 \\
\hline \multicolumn{7}{|l|}{ Рахит } \\
\hline I степени & 7 & 6,3 & 1 & 2,1 & 12 & 10,1 \\
\hline ॥ степени & 34 & 30,9 & 10 & 21,3 & 35 & 29,4 \\
\hline Остаточные явления & 6 & 5,5 & 4 & 8,5 & 9 & 7,6 \\
\hline \multicolumn{7}{|l|}{ Гипотрофия } \\
\hline | Степени & 8 & 7,3 & 10 & 21,3 & 9 & 7,6 \\
\hline ॥ Степени & 14 & 12,7 & 5 & 10,6 & 25 & 21 \\
\hline III Степени & 13 & 11,8 & 2 & 4,3 & 9 & 7,6 \\
\hline тДС & 8 & 7,5 & 2 & 4,3 & 5 & 4,2 \\
\hline \multicolumn{7}{|l|}{ Поражение ЦНС: } \\
\hline Энцефалопатия & 9 & 8,2 & 3 & 6,4 & 5 & 4,2 \\
\hline Гипоксическая & 27 & 24,5 & 12 & 25,5 & 25 & 21 \\
\hline Перинатальная & 35 & 31,8 & 15 & 31,9 & 37 & 31,1 \\
\hline Токсическая & 23 & 20,9 & 9 & 19,1 & 24 & 20,7 \\
\hline Анемия & 64 & 58,8 & 25 & 53,9 & 57 & 47,9 \\
\hline Аллергический диатез & 7 & 6,4 & 6 & 12,8 & 9 & 7,6 \\
\hline Грудное вскармливание & 18 & 16,4 & 6 & 12,8 & 19 & 16 \\
\hline Искусственное вскармливание & 51 & 46,4 & 22 & 46,8 & 54 & 45,4 \\
\hline Смешанное вскармливание & 41 & 37 & 19 & 40,4 & 46 & 38,7 \\
\hline
\end{tabular}

Как видно из таблицы 2, из отягощяющих факторов на развитие неотложных состояний при ОКИ у детей раннего возраста оказало влияние порядковый номер беременностей (2 и более) и родов (2 и более), наличие токсикоза 1-ой половины беременности, перенесенные заболевания (асфиксия новорожденных, асфиксия +энцефалопатия и др.), которые являлись превалирующими при бактериальных и бактериальновирусных кишечных инфекциях, а остальным факторам отводилась меньшая роль при них. При ОКИ бактериальной и бактериально - вирусной этиологии развитию неотложных состояний способствовали заболевания преморбидного фона, которые были проанализированы в зависимости от характера вскармливания, что представлено на рисунке. 


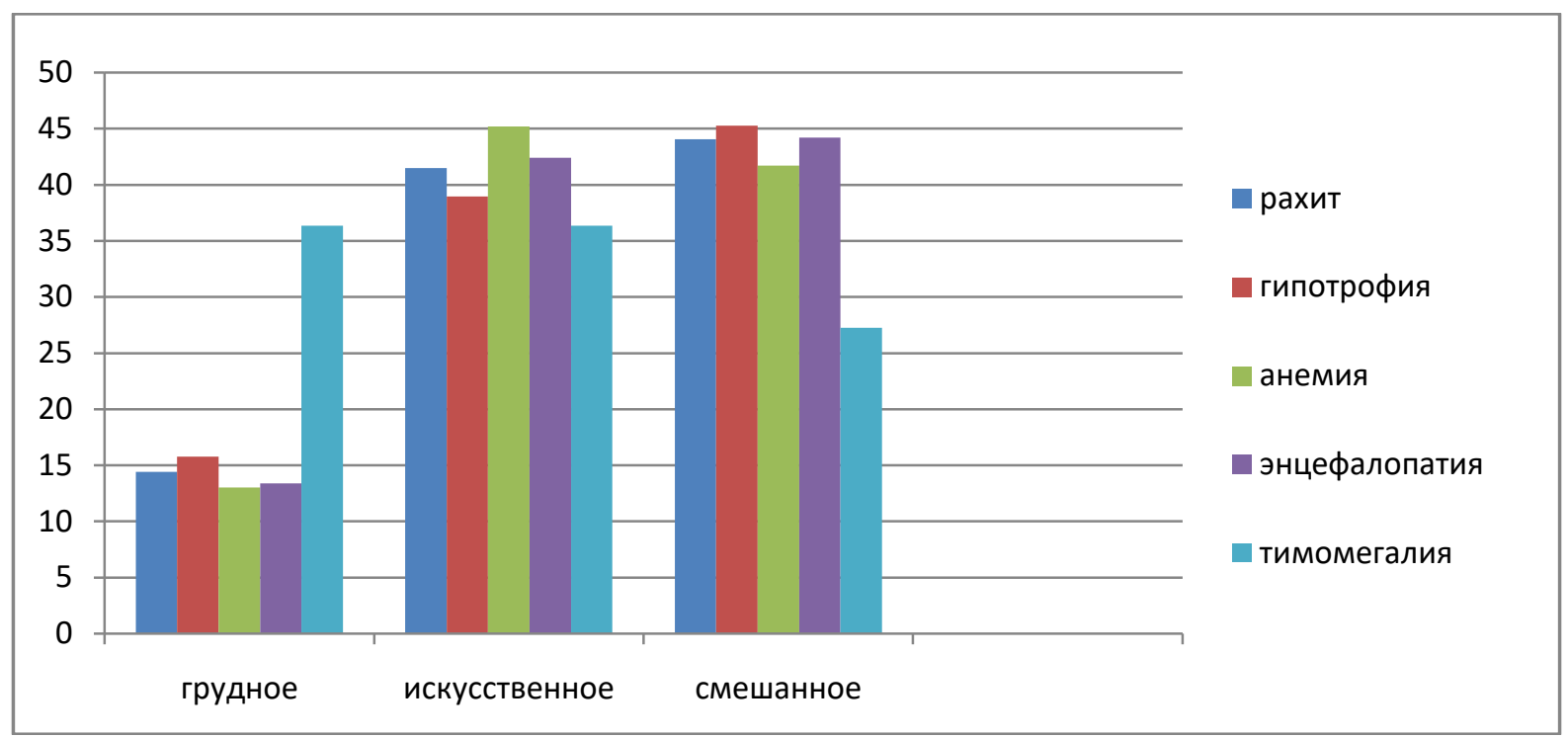

Puс. Влияние преморбидного фона на развитие неотложных состояний в зависимости от характера вскармливания

Как видно из рисунка, из 224 больных с поражением ЦНС большая часть больных находилась на смешанном $(44,2 \%)$ и искусственном $(42,4 \%)$ вскармливании, значительно меньше получали грудное вскармливание - 13,3\%. Второе же место по частоте заболеваний преморбидного фона занимала анемия при искусственном вскармливании - 45,2\%, меньше на смешанном - 41,7\% и значительно реже при грудном вскармливании - 13,\%. Что касается рахита, то наибольшая частота отмечена при смешанном вскармливании - у 44,1\%, далее на искусственном - у $41,5 \%$ и реже при грудном - у $14,5 \%$ детей. Влияние смешанного вскармливания на развитие гипотрофии отмечено у 45,3\% больных, при искусственном вскармливании она развивалась в $38,9 \%$ случаях, значительно реже на развитие гипотрофии влияло грудное вскармливание - 15,8\%. В то же время выявлено, что на развитие аллергического диатеза тип вскармливания не оказывал значительного влияния: при грудном - у 36,4\%, искусственном - у 36,4\%, смешанном - у 27,3\% больных.

Грудное вскармливание снижает заболеваемость ОКИ грудных детей. Это подтверждается тем, что у детей первых 3 мес., находящихся на грудном вскармливании частота заболеваемостью ОКИ значительно ниже по сравнению с детьми, находившиеся на искусственном вскармливании.

Bblвoдbl

Таким образом, среди отягощающих факторов в развитии неотложных состояний при ОКИ введущее место у детей первых 6 месяцев жизни отводится поражениям ЦНС при искусственном и смешанном вскармливаниях, а у детей в возрасте от 7 до 12 месяцев - рахит и гипотрофия также при искусственном и смешанном вскармливаниях. Факторы, способствующие развитию неотложных состояний у детей раннего возраста при ОКИ усугубляют имеющийся физиологический иммунодефицит, так называемый «иммунологический провал», гипотрофия II-II степени, сопровождающаяся синдромом мальабсорбции, а тяжелый рахит - дефект метаболизма витамина $D$ при кишечных инфекциях бактериальной и бактериальновирусной этиологий приводят к неотложным состояниям у детей раннего возраста.

\section{Литература}

1. Афанасьева О.И., Королева Е.Г., Дриневский и др. Отягощенный преморбидный фон, как фактор риска неблагоприятного течения гриппа у детей //Детские инфекции, 2011, №4, с.25-28.

2. Блохин Н.Н. Неотложная педиатрия. Национальное руководство, 2019.

3. Веселова О.А., Коновалова Т.А., Яковенко М.Л., Подколзин А.Т. Анализ этиологии летальных исходов на фоне острых диарейных заболеваний у детей младшего возраста в Российской Федерации 2012 - 2013 гг. /Матер. VIII Всероссийской Научнопрактической конференции с международным участием, 2014, т.1, с.366 - 368.

4. Веселова О.А., Гусева А.Н., Подколзин А.Т., Шипулин Г.А., Сравнительная этиологическая структура острых диарейных заболеваний у детей по данным госпитализации и амбулаторного приема /Матер.VIII Всероссийской Научно-практической конференции с международным участием, 2014, т.1, c.371- 372 .

5. Гончарь М.А., Завгородний И.В., Битчук Н.Д. и др. Неотложные состояния в педиатрии. Метод. указания, Харьков, 2017, 75 с.

6. Григорович М.С. Функциональное состояние желудочно-кишечного тракта и особенности исходов при острых кишечных инфекциях // 
Эпидемиология и инфекционные болезни, 2012, №3, c.56- 59.

7. Мазанкова Л.Н., Юнес Б., Курахтина И.С., Храмова Е.Н. Совершенствование дифференциальной диагностики ОКИ различной этиологии у детей // Детские инфекции, 2010, с.57.

8. Николаева И.В. Формирование кишечной микрофлоры ребенка: факторы, влияющие на этот процесс // Детские инфекции, 2011, №3, с.39 - 42.

9. Никольская Т.И., Куприенко Н.Б., Белякова А.В., Степанова М.Н. Неотложная помощь в педиатрии. Пособие, С.-Петербург, Издательство СПбГМУ, 2010, $42 \mathrm{c}$.

10. Усенко Д.В., Плоскирева А.А., Горелов А.В. Острые кишечные инфекции у детей в практике педиатра: возможности диагностики и лечения //Вопросы современной педиатрии, 2014, т.13, c. 12-20.

11. Diarrheae (Information bulletein), WHO, 2018.

12. Lanata C., Walker C. et al. Child Health epidemiology reference group of the $\mathrm{WHO}$ and UNICEF. Global causes of diarrheal disease morbidity in children $<5$ years of age // Plos One, 2013, 8(9), p.727-88. 